LA-UR-gr- 7664

Title:

Author(s):

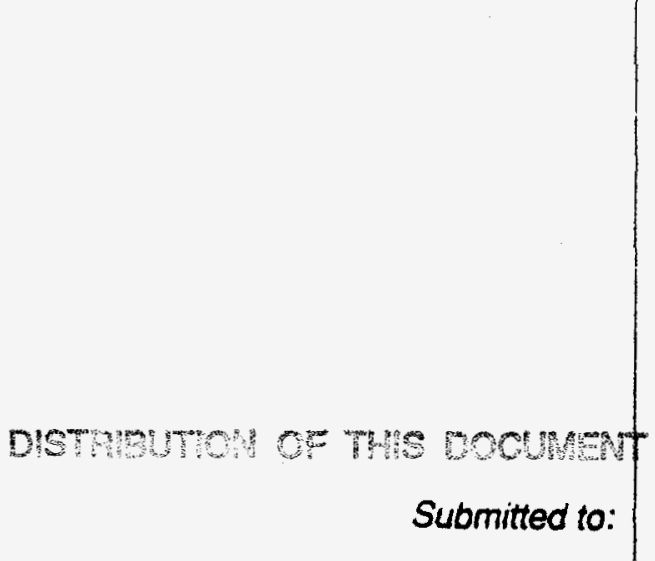

CONF-970503--222

MULTI-KILOAMPERE, ELECTRO-BEAM GENERATION

FROM BARE ALUMINUM PHOTO-CATHODES DRIVEN

BY AN ARF LASER

\section{RECEIVED \\ AUG 141997 \\ OSTI}

R. L. CARSON, R. N. RIDLON, G. J. SEITZ, AND T. P. HUGHES
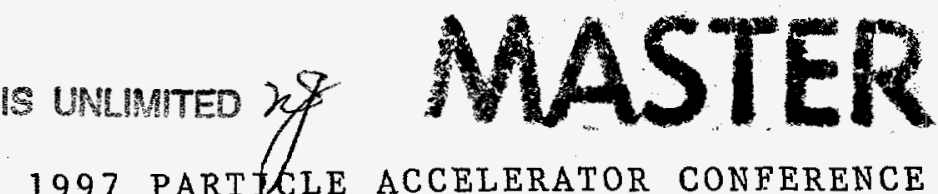

1997 PART CLLE ACCELERATOR CONFERENCE

\section{DISCLAIMER}

This report was prepared as an account of work sponsored by an agency of the United States Government. Neither the United States Gnvernment nor any agency thereof, nor any of their employees, makes any warranty, express or implied, or assumes any legal liability or responsibility for the accuracy, completeness, or usefulness of any information, apparatus, product, or process disclosed, or represents that its use would not infringe privately owned rights. Reference herein to any specific commercial product, process, or service by trade name, trademark, manufacturer, or otherwise does not necessarily constitute or imply its endorsement, recommendation, or favoring by the United States Government or any agency thereof. The views and opinions of authors expressed herein do not necessarily state or reflect those of the United States Government or any agency thereof.

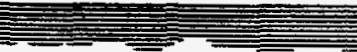
$\equiv$

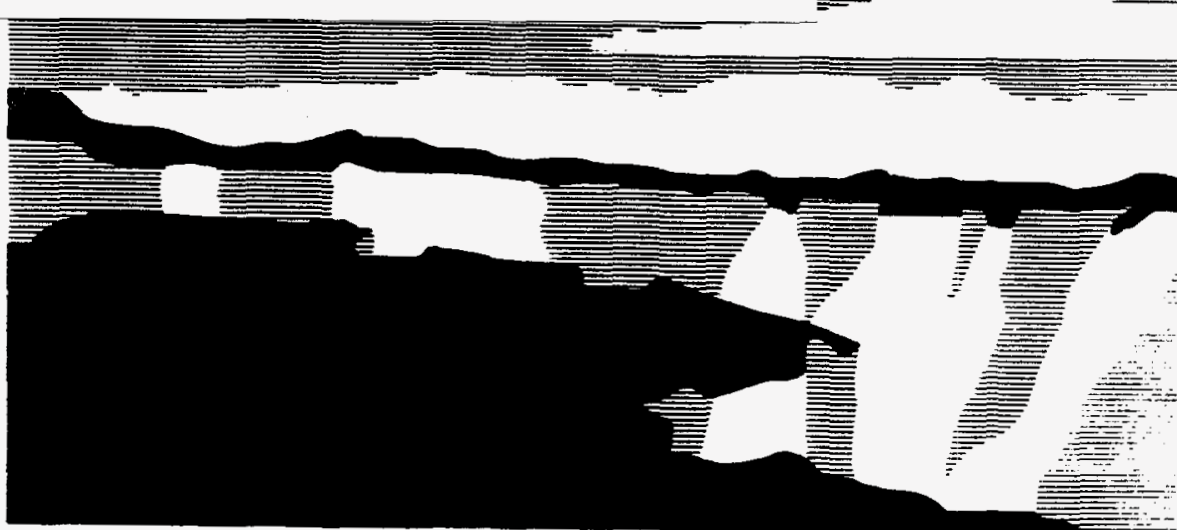

Los Alamos National Laboratory, an atfirmative actionvequal opportunity employer, is operated by the University of California for the U.S. Department of Energy under contract W-7405-ENG-36. By acceptance of this arvcle. the publisher recognizes that the U.S. Govemment retains a nonexchusive, royalty-free license to publish or reproduce the published form of this contribution. of to allow others to do so, for U.S. Governmemt purposes. The Los Alamos National Laboratory requests that the publiaher identhy this article as work performed under the auspices of the U.S. Department of Energy. 


\section{DISCLAMIER}

Portions of this document may be illegible in electronic image products. Images are produced from the best available original document. 


\title{
Multi-Kiloampere, Electron-Beam Generation from Bare Aluminum Photo- Cathodes Driven by an ArF Laser
}

\author{
Randolph L. Carlson, Rae N. Ridlon, and Gerald J. Seitz \\ Los Alamos National Laboratory, Los Alamos, New Mexico, 87545, USA \\ Thomas P. Hughes \\ Mission Research Corporation, Albuquerque, NM 87106
}

Abstract

An electron-beam-pumped laser operating at $\operatorname{ArF}(193 \mathrm{~nm})$ producing up to 5.0 joules in a 150 -ns pulse has been used to illuminate micro-machined aluminum cathodes. The cathode was pulsed from 2.25- up to $2.95-\mathrm{MV}$ across a $20-\mathrm{cm}-\mathrm{AK}$ gap producing fields up to $145 \mathrm{kV} / \mathrm{cm}$ using REX (a 4-MeV, 5-kA, 100-ns pulsed diode). Extracted current versus laser power gives a quantum efficiency increasing with power density from 0.07 to 0.11 percent. The present work is significant in that the cathode operates in the presence of outgassing materials with a background vacuum pressure in the mid $10^{-6}$ torr region and 100-ns-long electron beams of up to $3 \mathrm{kA}$ have been produced. Both emission limited (current follows laser pulse) and space-charge-limited (current follows pulsed power) regimes have been studied up to $\sim 50 \mathrm{~A} / \mathrm{cm}^{2}$ by varying the cathode diameter. The beam temperature has been measured to be $<5 \mathrm{eV}$ and directly compared in the same experimental setup to velvet based cathodes that measure $\sim 100 \mathrm{eV}$.

\section{INTRODUCTION}

This work is a continuation of experiments reported in [1] with higher laser power illumination of the diamond turned ( $\sim 0.5 \mu \mathrm{m}$ finish), 6061-T6, aluminum alloy cathodes. In addition, the measurement of the effective electron beam temperature of the cathode source has been made.

The primary advantage of a cathode utilizing the photoelectric effect from bare metals as compared to the more conventional photo-alkali or thermionic sources is the ability to have the cathode function in a modest vacuum environment $\left(\sim 10^{-6}\right.$ torr $)$. The disadvantage is that high laser energies $(\sim$ joules) are required to drive multi-kA beams over 100 -ns-long time periods as required of our present application $[2,3]$. Other researchers have investigated means of increasing the quantum efficiency by heating [4] or preferentially grooving [5] aluminum cathodes to increase the probability that an electron escapes the metal surface. The quantum efficiency, $\mathrm{QE}$, is defined in this paper as: $\mathrm{QE}=(\mathrm{I} / \mathrm{P})(\mathrm{eV} /$ photon $)$ where $I$ is the emitted beam current, $P$ is the laser power incident on the cathode, and the energy/photon is $6.42 \mathrm{eV}$. Small-scale, short-pulse, ArF studies are ongoing to address the relative QE's of other candidate metals and films, their preparation, and the effects of temperature, vacuum, and mono-layer contaminants [6].

\section{EXPERIMENTAL TEST SETUP}

Figure 1 shows the REX Facility [7] comprising an E-beam diode, excimer laser with beam paths, and diagnostics. The laser beam was directed by a turning mirror, focused toward a second turning mirror, through a window, and onto the cathode for beam temperature measurements. An elliptical aperture (2:1 aspect ratio) was used at the entrance window to make the beam circular on the cathode. To measure QE's at normal incidence, an alternate beam path utilized a turning mirror and lens combination that directed the laser beam through the entrance window of the test section that contained the E-beam mask and scintillator hardware.

The energy and spatial profile of the laser beam were recorded at the cathode conjugates by an Energy Monitor (Pyrex based, Scientech Inc., 10-cm absorbing calorimeter) and a Profile Monitor (Star Tech Instruments Inc., BIP$3100 / \mathrm{Z} 6 / \mathrm{F} 100,10-\mathrm{cm}$, UV to CCD converter). The laser light was monitored by vacuum photo-diodes (see Fig. 1) at the source (SAM PD) and cathode (REX PD). Beam current was monitored $5 \mathrm{~cm}$ after the anode aperture and $125 \mathrm{~cm}$ from the cathode at the test section entrance with beam size controlled by the anode extraction magnet. The AK gap voltage was monitored by an array of four, integrated E-Dots flush-mounted on the anode face and were cross-calibrated by an energy spectrometer. Beam temperature diagnostics included a 3.2-mm-thick brass E-beam mask (located $160 \mathrm{~cm}$ from the cathode) containing an array of fifteen 1-mm-diam holes spaced on 10-mm centers except for a 2-mm-diam reference hole $2 \mathrm{~cm}$ on either side of center. Electrons transmitted through the array of holes drifted either 30,50 , or $85 \mathrm{~cm}$ to a strip of 0.5 -mm-thick Bicron 422 scintillator. The resulting light was recorded on Kodak T-MAX 400 film by a Thompson-CSF, TSN-506-N streak camera located within a shielded screen room. The image was analyzed by techniques developed in $[8,9]$ and yields both space and time resolved beam temperature of the cathode source.

\section{QUUANTUM EFFICIENCY}

Figure 2 shows the voltage/current (VI) characteristics of a 6.35-cm-diam velvet cathode with the calculated [10] spacecharge-limited (SCL) current plotted in Fig. 3. At $2.25 \mathrm{MV}$ the calculation over-predicts the current by $10 \%: 1.360$ versus $1.215-\mathrm{kA}$ measured. The plot is very useful in estimating the effective beam diameter on the photo-cathode. 


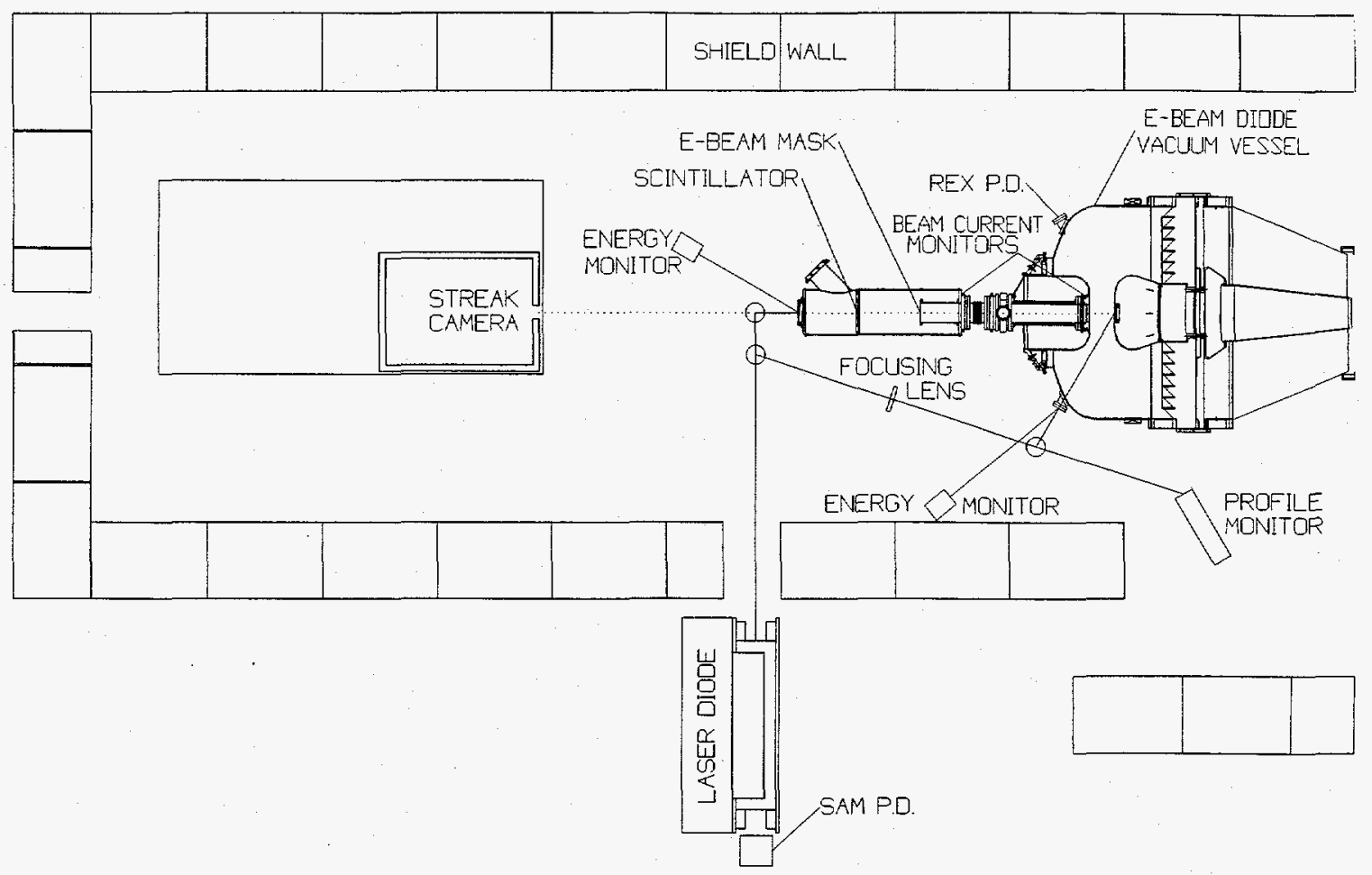

Figure 1. Layout of REX electron-beam facility with electron-beam-pumped excimer laser diode.

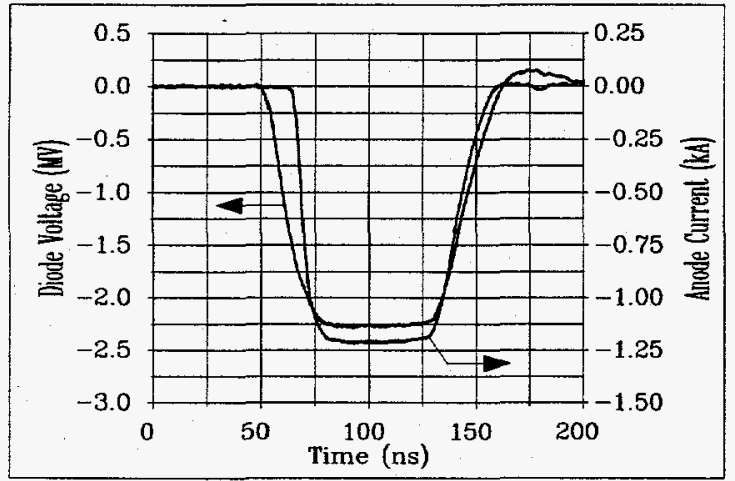

Figure 2. VI characteristics of 6.35 -cm-diam velvet cathode at $2.28 \mathrm{MV}$, AK gap is $20 \mathrm{~cm}$; note delay of diode turn-on.

For beam temperature and low laser power normal incidence experiments, the laser was focused to a $1 / \mathrm{e}^{2}$ diameter of 6.0 $\mathrm{cm}$ as measured by the Profile Monitor. The larger $(\sim 9.5 \mathrm{~cm})$ laser beam could only be estimated by imaging the visible light emission at the cathode. ArF propagation losses experienced in our previous work [1] were greatly reduced by moving the laser close to REX. As the laser power was increased from a few- to 30-MW, the current for each beam size approached the SCL current region (current follows voltage) as indicated by the current plateaus in Fig. 4. The $\mathrm{QE}$ is bounded by a value of $0.07 \%$ at the lower power

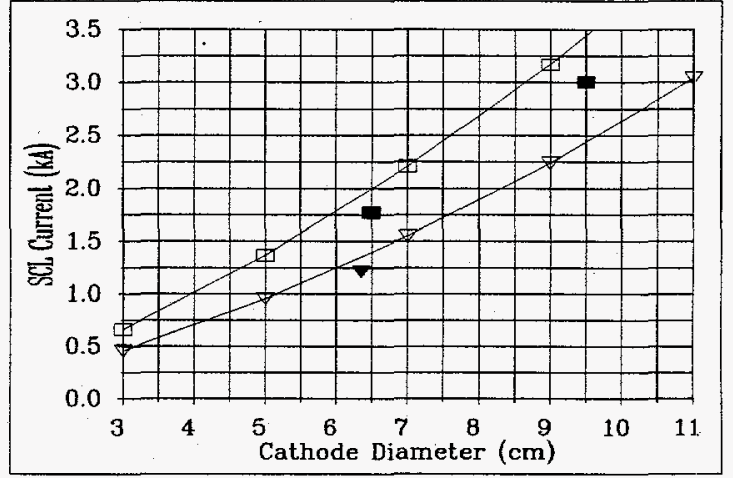

Figure 3. Calculated SCL current at 2.25- $(\nabla)$ and 2.90-MV

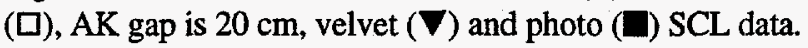

densities and by $0.11 \%$ at much higher power densities which is consistent with our previous work [1]. The SCL currents for this data are 1.77- and 3-kA. The anode current, diode voltage, and REX PD for the larger-beam case are shown in Fig. 5. At $28 \mathrm{MW}$ the laser power is $\sim 50 \%$ greater than that needed for SCL conditions. At 8.6 MW the current of 1.47 $\mathrm{kA}$ is emission limited (current follows laser). Other measurements at lower currents from 100- to 1200-A and laser powers from 1- to $10-\mathrm{MW}$ in a $6.0 \mathrm{~cm}$-diam beam gave QE's of 0.07 - and $0.078-\%$ for incident angles of normal and 60 degrees, respectively. 


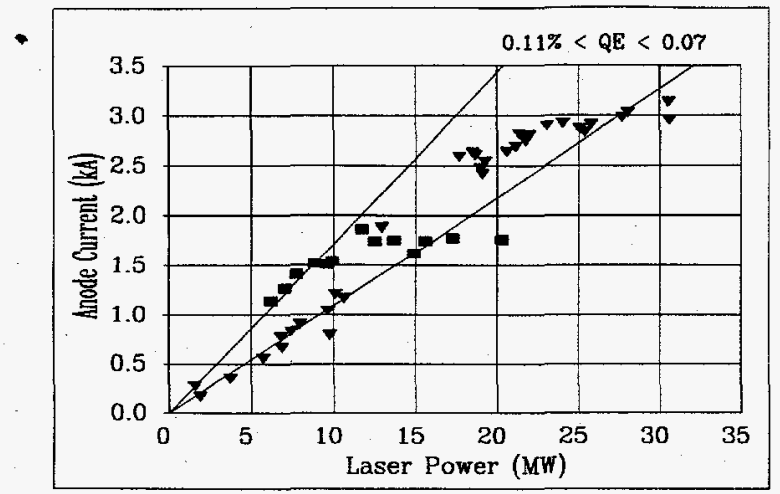

Figure 4. Anode current vs laser power at $2.95 \mathrm{MV}$, AK gap is $20 \mathrm{~cm}, 6.0-(\mathbf{C})$ and $9.5-\mathrm{cm}$-diam ( $\mathbf{\nabla})$ laser beams.

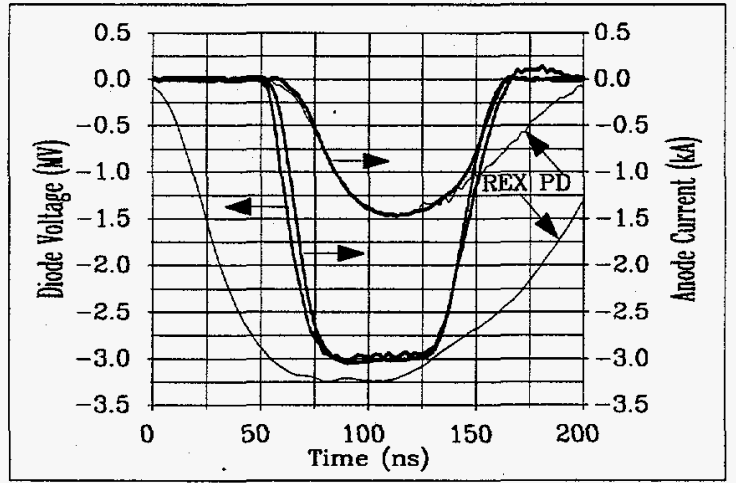

Figure 5. VI of photo-cathode at 8.6- and 28-MW.

\section{BEAM TEMPERATURE}

The effective beam temperature, $T_{\text {eff, }}$ is defined as: $T_{\text {eff }}=$ $0.511 \times 10^{6} \times\left(\beta \gamma \theta_{\text {rms }}\right)^{2} \mathrm{eV}$, where $\theta_{\text {rms }}$ is the rms angle of the distribution of the electrons on the scintillator due to the transverse momentum of the electrons created at the cathode and the self space charge of the beamlet as it drifts from the Ebeam mask hole. $\theta_{\text {rms }}$ must be modified by $R m / R c$ which is the ratio of the electron beam at the mask to the cathode. The scintillator was placed 30 - and $50-\mathrm{cm}$ from the E-beam mask for the velvet and 50 - and $85-\mathrm{cm}$ for the photo-cathode data. The resultant T-MAX film image was scanned by a PerkinElmer micro-densitometer with 10 - and $20-\mu \mathrm{m}$-square apertures for the photo-cathode and velvet data, respectively. The center three beamlets were each time averaged over a 10ns window, the data corrected for the film density versus exposure curve, and gaussians fit to each distribution. The resultant rms radii of the gaussians were used to calculate $\theta_{\mathrm{rms}}$ knowing the drift distance and $\mathrm{Rm} / \mathrm{Rc}$. The data were also corrected for the finite hole size in the mask; this effect is $20 \%$ for a $5 \mathrm{eV}$ beam drifting $85 \mathrm{~cm}$ with $\mathrm{Rm} / \mathrm{Rc} \sim 1$. Teff averaged over the center three beamlets for the photo-cathode

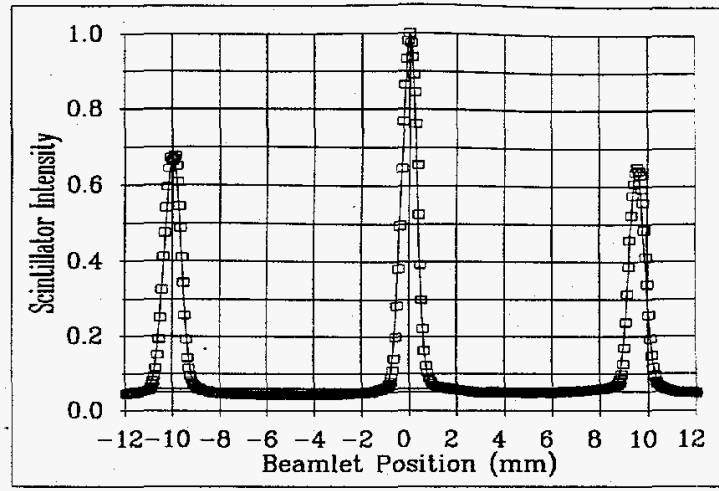

Figure 6. Gaussian fits of photo-cathode beamlet data ( $\square$ ) (averaged over $10 \mathrm{~ns}$ ) at $510 \mathrm{~A}$ and $2.28 \mathrm{MV}$, drift is $85 \mathrm{~cm}$.

data of Fig. 6 is $4 \mathrm{eV}$ which is at the limit of the present technique. The velvet data at $1.2 \mathrm{kA}$ gave $90-$ and $85-\mathrm{eV}$ at $30-$ and $50-\mathrm{cm}$, respectively. The value of Teff remained constant spatially and temporally across the flat-top portion of the beam.

In summary, multi-kA ( $3 \mathrm{kA}), 100$-ns-long beams can be produced with an $\mathrm{ArF}$ laser at a $\mathrm{QE} \sim 0.1 \%$ on bare aluminum. The beam temperature of the photo-cathode was measured to be $<5 \mathrm{eV}$ for currents $\sim 500 \mathrm{~A}$ at $2.28 \mathrm{MeV}$.

\section{ACKNOWLEDGMENTS}

This work was supported under the auspices of the U.S. Department of Energy.

\section{REFERENCES}

[1] R.L. Carlson, et al: BEAMS'96, Proc. 11th International Conference on High Power Particle Beams, pp. 188-191.

[2] M. Burns, et al: LINAC'96, Proc. 18th International LINAC Conference.

[3] T.P. Hughes, D.C. Moir, and P.W. Allison: Proc. 1995 IEEE Particle Accelerator Conference, pp. 1207-1209.

[4] R.P. Shurter, et al: BEAMS'96, Proc. 11th International Conference on High Power Particle Beams, pp. 993-998.

[5] T. Tanabe, Y. Kawamura, D. Li, and K. Toyoda: Rev.Sci.Instrum. 66 (2), (1995), pp. 1010-1014.

[6] R.P. Shurter, et al: paper at this conference.

[7] R.L. Carlson, T.J. Kauppila, and R.N. Ridlon: Proc. 1991 IEEE Pulsed Power Conference, pp. 82-85.

[8] T.P. Hughes, R.L. Carlson, and D.C. Moir: J.Appl.Phys. 68 (6), (1990), pp. 2562-2571.

[9] T.J. Kauppila, R.L. Carison, et al: Proc. 1991 IEEE Particle Accelerator Conference, pp. 2107-2109.

[10] PBGUNS Code developed by J. Boers: Proc. 1993 IEEE Particle Accelerator Conference, pp. 327-332. 